\title{
Synovial Sarcoma- An unusual cause of Heel Pain
}

\author{
MY Norhamdan, MS (Ortho), Y Shahril, MS (Ortho), O Masbah, MS (Ortho), Siti Aishah MA*, MIAC \\ Department of Orthopaedics \& Traumatology, UKM Medical Centre, Kuala Lumpur, Malaysia \\ * Department of Pathology, UKM Medical Centre, Kuala Lumpur, Malaysia
}

\begin{abstract}
We report a case of 29-year-old female who presented with right heel pain that worsened over a period of two years. The onset of pain was followed by swelling at the medial aspect of right ankle. She was initially treated for plantar fasciitis with multiple steroid injections over the heel. Subsequent MRI revealed a well-defined heterogeneous lesion in continuity with the medial plantar nerve. Excision biopsy was performed and histopathological evaluation revealed monophasic synovial sarcoma. The patient subsequently underwent wide resection and free tissue transfer followed by radiotherapy and chemotherapy. This case highlights an unusual site and presentation of synovial sarcoma which led to delayed diagnosis and treatment.
\end{abstract}

Key Words:

Heel pain, Monophasic synovial sarcoma, Wide resection

\section{INTRODUCTION}

Plantar heel pain is one of the most commonly seen conditions seen in orthopaedic practice. Causes of heel pain include plantar fasciitis, tarsal tunnel syndrome and entrapment neuropathies, however lesions proximal to the heel should not be excluded as a cause of such discomfort. This case highlights the atypical presentation of synovial sarcoma which led to a delay in diagnosis and treatment. Suggestions are put forth to prevent such delays in the future.

\section{CASE REPORT}

A 29-year-old female presented with a history of pain over the plantar aspect of the right foot for two years. She described the pain as localized, intermittent and was aggravated by prolonged weight bearing. A diagnosis of plantar fasciitis was previously made; in fact, several doctors had treated the patient with steroid injections in her right heel, but the symptoms persisted. The pain increased in severity and was worse at night, and the patient now noticed a swelling over medial aspect of the right foot. Examination revealed a nontender subcutaneous swelling below the medial malleolus that measured $2 \times 1 \mathrm{~cm}$, and was fixed to the underlying structure (Figure 1). Magnetic resonance imaging revealed a well-circumscribed heterogeneous lesion, isointense to muscle on $\mathrm{T}(1)$-weighted image and hyperintense on $\mathrm{T}(2)$ image indicating a benign lesion (Figure 2). Due to close proximity to the posterior tibial nerve, the patient was diagnosed with neuroma.

The patient underwent excision biopsy and intra-operatively the lesion was noted to be a soft, friable mass encasing the medial plantar nerve (Figure 3). Histopathological evaluation revealed monophasic synovial sarcoma as evidenced by spindle-shaped and neoplastic cells. Imunohistochemically the neoplastic cells were positive for vimentin and focally positive for EMA, CK, and CD 99 but negative for $\mathrm{CD} 34, \mathrm{CD} 31$, desmin, myoglobin, smooth muscle actin, factor 8 antigen and S-100 protein.

Unfortunately, local recurrence developed in less than three months after initial surgery necessitating wide resection. The entire biopsy tract, medial plantar nerve, posterior tibial artery, plantar fascia and adductor hallucis longus were removed together with the tumour (Figure 4). The soft tissue defect was reconstructed with a vascularised transverse rectus abdominis perforator flap. Surgical margins were histologically free of tumour. Postoperatively the patient received 60 grays (Gy) of local radiotherapy followed by six cycles of cisplatin, adriamycin and ifosfamide chemotherapy. At two year after surgery, she has good local control and no evidence of metastases.

\section{DISCUSSION}

Soft tissue sarcomas (STSs) are rare malignancies that arise from mesenchymal tissues most commonly in the head and neck, retroperitoneum, and extremities. When they arise in the extremities, they most often are located proximal to the hip or shoulder region ${ }^{1}$. Synovial sarcoma is a soft tissue sarcoma with features of epithelial differentiation. It is a high-grade sarcoma, characterised by local invasiveness and a tendency to metastasize early.

Soft tissue sarcoma of the foot and ankle is rare and usually presents as a slow growing mass. The mean duration from onset to diagnosis of synovial sarcoma in a painless mass is 20.8 months $^{2}$. In our patient, the delay in diagnosis occurred 


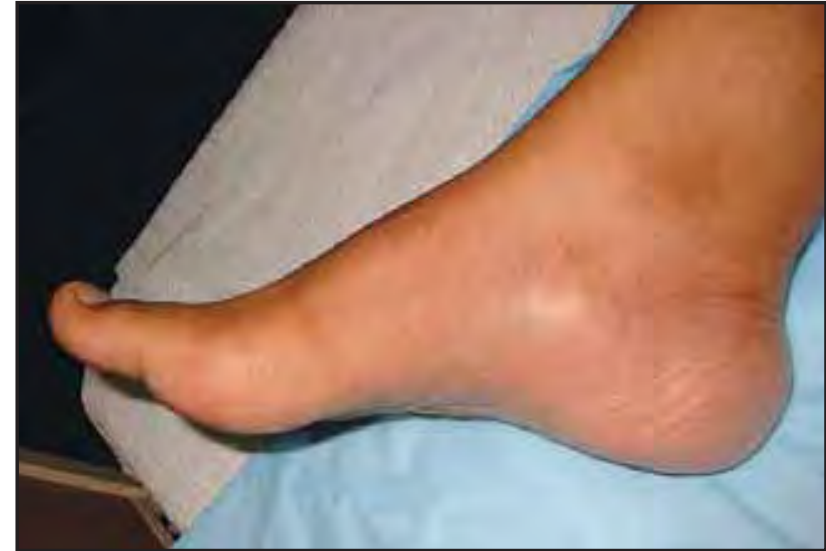

Fig. 1: Clinical presentation showing mass below the medial malleolus.

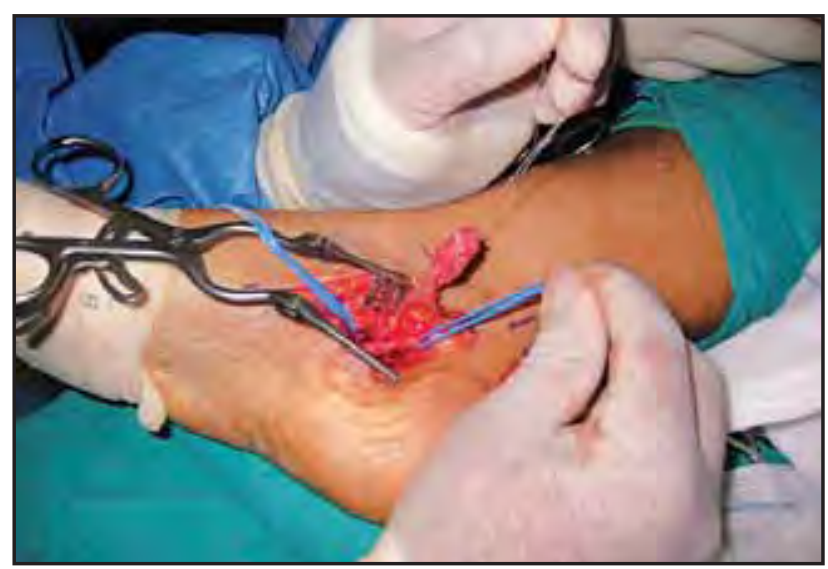

Fig. 3: Intra-operative photograph of excision biopsy. The mass was fixed to the medial plantar nerve and was composed of both solid and cystic components.

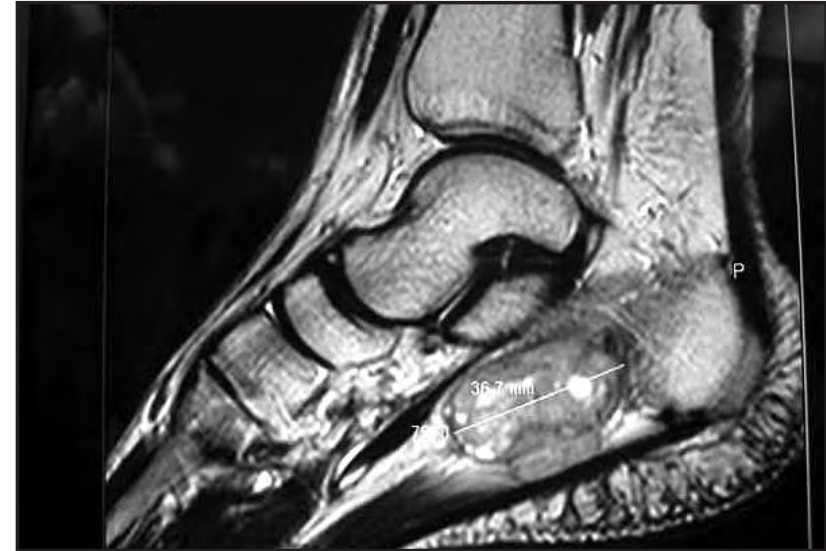

Fig. 2: Preoperative: MRI appearance of the mass showed well circumscribed lesion.

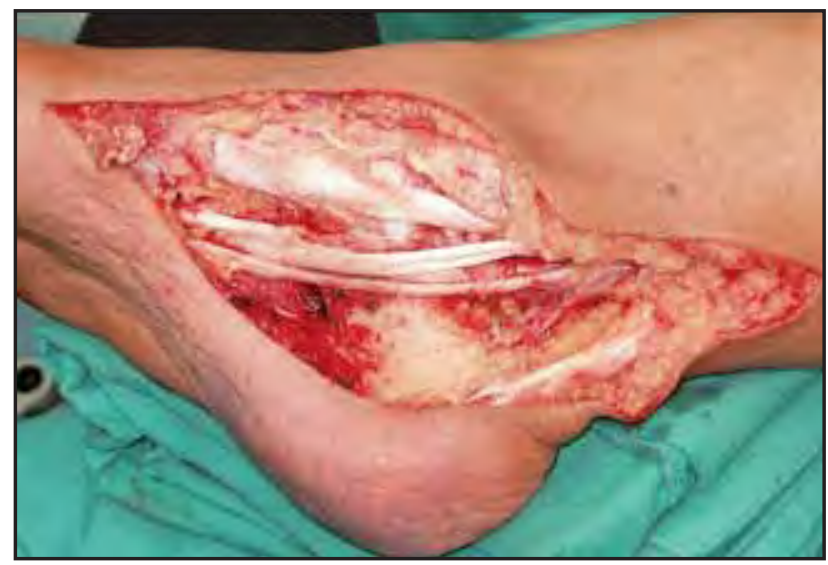

Fig. 4: Wide resection of the tumour: posterior tibial artery has to be sacrificed due to closed proximity to the tumour. Abductor hallucis and calcaneal periosteum removed to improve surgical margin. Flap procedure performed due to exposed structures and to prevent wound dehiscence during radiotherapy.

Surgical resection remains the cornerstone of treatment for synovial sarcoma ${ }^{5}$. In this patient, the recurrent lesion after initial surgery did not preclude limb salvage surgery if a wide margin of resection could not otherwise be achieved. The resulting soft tissue defect was reconstructed with a fasciocutaneous paddle, providing a reliable cover for primary healing. Composite tissue transfer is another possibility soft tissue cover around joints, particularly the foot that would not have been adequately protected with a skin graft. Free tissue transfer increases the versatility of extremity reconstruction and minimizes infection, as shown in this patient.

\section{ACKNOWLEDGMENT}

The authors would like to thank Dr Faisham WI, Prof Zulmi Wan, Dr Ahmad Sukari Halim from Hospital Universiti Sains Malaysia for providing clinical material and involvement in the treatment of this patient. 


\section{REFERENCES}

1. Gerrand CH, Wunder JS, Kandel RA, O'Sullivan B, Catton CN, Bell RS et al. The influence of anatomic location on functional outcome in lower-extremity soft-tissue sarcoma. Ann Surg Oncol 2004; 11: 476-82.

2. J. Vilá, R. Larrainzar, LF Llanos, FJ Martinez-Tello. Synovial sarcoma of the foot: a review of five cases. J Foot Ankle Surg 1999; 4: 191-6.

3. Kirby EJ, Shereff MJ, Lewis MM. Soft-tissue tumors and tumor-like lesions of the foot: an analysis of eighty-three cases. $J$ Bone Joint Surg 1989; 1(A): 621-6.

4. M Mercuri, R Casadei. Tumours in the foot. J Foot Ankle Surg 2002; 8: 175-90.

5. Ferguson PC. Surgical considerations for management of distal extremity soft tissue sarcomas. Curr Opin Oncol 2005; 17 : 366 -9. 